\title{
The comparison of the environmental impact of steel and vinyl sheet piling: life cycle assessment study
}

\author{
A. Marcinkowski ${ }^{1}$ (D) J. Gralewski ${ }^{1}$ (D)
}

Received: 7 February 2020 / Revised: 20 March 2020 / Accepted: 13 April 2020 / Published online: 25 April 2020

(c) The Author(s) 2020

\begin{abstract}
The literature review concerning various materials for production of sheet piles used in wet ground, waterfront and marine conditions has been presented. Polyvinyl chloride has been identified as a promising steel alternative. Despite unambiguous findings suggesting a higher environmental impact of steel sheet piles compared to polymer products, the necessity of further detailed surveys, confirming the preliminary conclusion, has been perceived. The main objective of this study has been to compare the environmental impact of steel and vinyl sheet piles taking into consideration various corrosion rate depending on the local conditions. The comparative life cycle assessment analyses have been carried out according to a cradle-to-site approach. The comparison of indicators has shown that the environmental impact of polymer products had been significantly lower than that of steel products. In case of the most aggressive environment, the differences of results have reached an order of magnitude. The dominant environmental impact has resulted from the production process of sheet piles. An uncertainty analysis has been carried out by means of Monte Carlo simulations. The study has also provided sensitivity analysis to the assumptions of the model applied. The minimum thickness of steel sheet piles after 50 years of use, including loss allowances and protective coatings, as well as different parameters of transport has been analyzed. Irrespective of the assumed conditions, the general conclusion has remained the same: steel sheet piles indicated significantly higher environmental impact than vinyl sheet piles.
\end{abstract}

Keywords Corrosion $\cdot$ Life cycle assessment $\cdot$ Polymer sheet piles $\cdot$ Polyvinyl chloride $\cdot$ Steel sheet piles

\section{Introduction}

Some types of terrain require particular measures of protection against erosion. In particular, they are required by waterfront areas where waves and tides have a destructive effect on backshore areas. A typical method of protection in such locations is the installation of seawalls that are modular waterfront structures constructed of sheet piles (Vaidya et al. 2005a, 2005b). Traditionally sheet piles are produced using conventional construction material such as steel. This material is characterized by satisfactory mechanical strength,

Editorial responsibility: M. Abbaspour.

A. Marcinkowski

andrzej.marcinkowski@p.lodz.pl

1 Faculty of Management and Production Engineering, Institute of Social Sciences and Management of Technologies, Lodz University of Technology, Łódź, Poland but at exploitation stage it causes problems associated with corrosion.

There are a number of studies describing the corrosion rate of steel sheet piling. The authors of the publication point out that the rate of corrosion depends on the location specificity and loading conditions. The type of environment (dry and wet soil, fresh and sea water) as well as its physicochemical variables $(\mathrm{pH}$, resistivity, redox potential, electric potential at the soil-metallic structure interface) and exposure time influence the dimensions of corrosion loss (Houyoux et al. 2007; Alamilla et al. 2009).

The traditional approach for providing the durability of steel sheet pile walls assumes the use of secondary corrosion protection measures such as protective coatings, cathodic protection systems or corrosion loss allowances. Nevertheless, neither of the first two options are very effective in constructions situated above the water surface especially in the long term (Ferguson and Trewern 2015). Corrosion allowances can be considered as the only effective measure to prolong the life of the steel piling structure; however, this 
solution requires the use of additional steel thickness that results in a significant increase in the amount of material consumed. The values for the loss of thickness due to corrosion for sheet piles situated in soils, fresh water and sea water for different time periods from 5 to 100 years have been estimated within European research project (Houyoux et al. 2007). The European standard EN 1993-5 has presented the values as recommended corrosion allowances (European Committee for Standardization 2007). Depending on the type of the environment, the allowances for 100 year period range from $1.2 \mathrm{~mm}$ (in case of undisturbed natural soils like sand, silt, clay, schist) up to $7.5 \mathrm{~mm}$ (for sea water in temperate climate in the zone of low water and splash zones). The values of thickness losses due to corrosion have been confirmed by later study (Wall and Wadso 2013). Despite the allowances applied, the corrosive processes result in the necessity to replace the sheet piles after the assumed time; otherwise, the waterfront wall could be damaged and would no longer perform its function. However, replacement of worn-out steel sheet piles during a structure's life is often either impossible or not practicable (Ferguson and Trewern 2015).

With regard to described problems related to the application of steel in aggressive environments, alternative materials for construction of structures used in wet ground, waterfront and marine conditions have been analyzed (Dunalska et al. 2015; Gerritsen et al. 2014; Parker 1992; Scuero and Vaschetti 1997; Bardakjian and Olmos 2018). Comparative tests have been carried out on infrastructure to be used in aggressive environment made of steel, cast iron, polyvinyl chloride (PVC), polyethylene (PE), composites, etc. (Vaidya et al. 2005b; Tang et al. 2006; Beamer and Kendall 2009). Some results of the researches indicate that PVC is a promising material for the production of sheet piles. Vinyl sheet piles exhibit substantial mechanical strength as well as high resistance to corrosion, UV radiation and other environmental factors (Vaidya et al. 2005b; Dutta and Vaidya 2003; Ferguson and Trewern 2015).

Nowadays, besides utility features and financial issues, the environmental impact is an increasingly important criterion for product selection. Some of the recognized properties of the examined types of sheet piles have distinct environmental implications. Given the lower plastic density compared to steel density, the weight of PVC sheets is expected to be much lower than that of steel sheets of the same mechanical strength. As the result, in case of PVC, the amount of material needed to produce the waterfront wall is smaller, which may contribute to the reduction of environmental impact both at the stage of production of sheet piles and during the transport of products to the place of application. Contrary to steel sheet piles, vinyl products do not require application of corrosion allowances that considerably reduces the amount of material needed (especially in the case of the most aggressive waterfront conditions) which additionally contributes to the reduction of the environmental impact caused by the phase of sheet piles production. Corrosion of the metal eventually leads to the destruction of the seawalls, so they need to be replaced with new ones. The replacement of sheet piles multiplies the environmental impact of various phases of the life cycle. However, despite unambiguous findings suggesting a higher environmental impact of steel sheet piles compared to alternative products, the detailed determination and comparison of the environmental impact of steel and plastic sheet piles is more complex. This requires taking into consideration:

- Substantial differences in production technology for different materials (iron ore and crude oil extraction and processing),

- Multiple factors resulting from specific properties of materials used,

- Different environmental damage categories (resources consumption, emissions, etc.),

- The impact of subsequent life cycle phases of compared products.

Complex analyses including mentioned issues could be carried out applying the life cycle assessment (LCA) approach. However, the current literature indicates a shortage of published research results on the environmental impact of various types of sheet piles despite the growing importance of alternative materials used for their production and technical availability of LCA method. In order to fill this literature gap, the main objective of this work is to determine and compare the environmental impact of steel and PVC sheet piles using life cycle assessment method. The research was carried out at the Faculty of Management and Production Engineering of Lodz University of Technology at the turn of 2019 and 2020.

\section{Materials and methods}

LCA provides a very wide perspective that includes various life cycle phases, like:

- Acquisition of resources (metal ores, crude oil, coal extraction processes, etc.),

- Raw materials production, from which the final product is being made (production processes of metals, alloys, plastic, ceramic, etc.),

- Raw materials, materials and semi-products transport (influence of transport means on the environment),

- Final product manufacturing processes (direct environmental impact of the product manufacturer),

- Packaging production, 
- Product distribution (supplying the product to wholesaler's, chain stores and customers-environmental impact of transport),

- Phase of product usage (materials needed, energy consumption),

- Waste disposal (Marcinkowski and Zych 2017).

The life cycle assessment method is standardized, the principles and requirements are specified by the International Organization for Standardization (2006a, b). According to the standards, the LCA framework consists of four main stages:

- Goal and scope definition,

- Life cycle inventory,

- Life cycle impact assessment,

- Interpretation.

In this study the subsequent stages are included in the "Materials and methods" section (Goal and Scope Definition and Life Cycle Inventory) and the "Results and discussion" section (Life Cycle Impact Assessment and Interpretation).

The environmental impact assessment was analyzed according to a cradle-to-site approach (cradle-to-gate approach extended by transport of product to the destination waterfront site). The comparison of environmental impact of steel and PVC sheet piles was based on the fact that both products fulfill the same function. The functional unit was a $100 \mathrm{~m}$ long waterfront wall made of sheet piles with a vertical dimension of $5 \mathrm{~m}$ used for 50 years. The time period was determined on the basis of the warranty duration of vinyl sheet piles (see assumption 4 for detailed information). The assumed distance between sheet piles manufacturer and a place of waterfront construction was $500 \mathrm{~km}$.

It was considered that the thickness of steel sheet piles in the ground and water environment decreases over time due to corrosion. In order to determine the amount of material necessary to produce the sheet piles taking into account the corrosion processes, the following assumptions were made:

1. The minimum thickness of steel sheet piles after 50 years of use $t_{50}$ is $4.5 \mathrm{~mm}$. The assumed value was chosen as the mean of minimum thickness of cold formed steel sheet piles (3 mm) (ArcelorMittal 2019a) and minimum thickness of steel sheet piles produced by hot-rolling technology (6 mm) (ArcelorMittal 2019b). However, the specific value of $4.5 \mathrm{~mm}$ was assumed as a baseline thickness and the other values were also considered in the "Thickness of steel sheet after 50 years of use" section together with the analysis of the effect of this assumption on comparison results.

2. Allowances for steel corrosion are taken on the basis of the values of thickness losses recommended by the
European Committee for Standardization (2007) assuming symmetrical corrosion degradation:

- As the least aggressive environment (lae), undisturbed natural soils (sand, silt, clay, schist, etc.) was assumed, in which one-sided loss of thickness due to corrosion within 50 years $L_{\text {lae }}$ is $0.6 \mathrm{~mm}$.

- As the most aggressive environment (mae), sea water in temperate climate in the zone of high attack (low water and splash zones) was assumed, where one-sided thickness loss due to corrosive impact during 50-year time period $L_{\text {mae }}$ is $3.75 \mathrm{~mm}$.

3. The assumed initial thicknesses $t_{\text {init }}$ of steel sheet piles taking into account two first assumptions were determined by means of Eq. 1:

$t_{\text {init }}=t_{50}+2 L_{i}$

where $t_{50}$ is the minimum thickness of steel sheet piles after 50 years of use and the subscript $i$ denotes the type of the assumed environment.

Thus the assumed $t_{\text {init }}$ were as follows:

- For the least aggressive environment $t_{\text {init }}=5.7 \mathrm{~mm}$,

- For the most aggressive environment $t_{\text {init }}=12.0 \mathrm{~mm}$.

The products available on the European market whose parameters are close to the assumptions are hot-rolled steel sheet piles of two types, respectively:

- ArcelorMittal GU 6N 6/6 mm,

- Larssen 43 12/12 mm (InfraRentals 2019),

whose parameters were taken for further analyses. The environmental impact of industrial processes to produce the corresponding amount of hot-rolled steel sheets (including mining of iron ore and coal, extraction of limestone and dolomite, minerals transportation and processing, blast furnace, casting line and hot strip mill) was determined using the Ecoinvent 2.2 database (Frischknecht et al. 2005). According to the products specification, the mass of $1 \mathrm{~m}^{2}$ of sheet piles is $69.9 \mathrm{~kg}(\mathrm{GU} \mathrm{6N})$ and $166.0 \mathrm{~kg}$ (Larssen 43), respectively (InfraRentals 2019), so that the mass per functional unit is:

- $34.95 \mathrm{t}\left(69.9 \mathrm{~kg} / \mathrm{m}^{2} \times 100 \mathrm{~m} \times 5 \mathrm{~m}\right)$-for the least aggressive environment,

- $83 \mathrm{t}\left(166 \mathrm{~kg} / \mathrm{m}^{2} \times 100 \mathrm{~m} \times 5 \mathrm{~m}\right)$ - for the most aggressive environment.

- The alternative for steel products meeting the assumptions is a vinyl sheet pile of type GW-610/6.4. On the basis of the results of the aging tests, the manufacturer grants a 50-year durability warranty on the products 
due to declared resistance to bio-corrosion, rust, cracking, scratching, abrasion, sea water and UV rays (Pietrucha Group 2014). The product specification states that the mass of $1 \mathrm{~m}^{2}$ of sheet piles is $15.92 \mathrm{~kg}$ (Pietrucha 2018); hence, the mass per functional unit is: $7.96 \mathrm{t}$ $\left(15.92 \mathrm{~kg} / \mathrm{m}^{2} \times 100 \mathrm{~m} \times 5 \mathrm{~m}\right)$.

The remaining assumptions of the applied research model are:

5. The raw material for the production of vinyl sheet piles is polyvinyl chloride granulate. The environmental impact of industrial processes for manufacturing the respective quantity of PVC granulate (including acquisition of resources, transport and raw material production) was determined using the Ecoinvent 2.2 database (Frischknecht et al. 2005). The transformation of $1 \mathrm{t}$ of PVC granulate into vinyl sheet piles requires the consumption of $490 \mathrm{kWh}$ of electricity, which is converted into heat energy ultimately emitted to the environment as a waste heat flow.

6. It has been assumed that the means of transport of products are lorries with a load capacity of 24 tons and a total permissible mass exceeding 32 tons. The vehicles meet the EURO 4 emission standard and are operated in European conditions.

7. The environmental impact of the installation phase of both types of sheet piles has been assumed to be comparable, and therefore the installation processes have been excluded from the analysis.

8. It was assumed that there would be no impact of sheet piles on the environment during the use phase and afterwards besides loss of thickness due to corrosion which was considered by the model within production stage assuming thickness allowances (see assumptions 2 and 3).

Environmental impact analyses were carried out by means of SimaPro 7.3.0. software applying the ReCiPe Endpoint $(\mathrm{H})$ method using recommended procedures given European conditions (Europe ReCiPe H/A) to determine indicators for 17 characterization impact categories as well as 3 endpoint categories: human health, ecosystems and resources.

The environmental impact of industrial processes was determined using the Ecoinvent 2.2 database. The environmental impact of the electricity generation process was determined taking into account the energy mix for 27 countries of European Union. An uncertainty analysis associated with input parameters of the LCA model was performed using Monte Carlo simulations assuming 95\% level of confidence.

\section{Results and discussion}

\section{Baseline scenario}

The baseline scenario refers to the model conditions associated with the assumptions described in the "Materials and methods" section. The results obtained for this scenario were presented below.

Table 1 depicts characterization and normalization indicators for assumed types of steel sheet piles. Figure 1 illustrates the results for $\mathrm{GU} 6 \mathrm{~N}$ piles in the form of process networks with the indicators for human health, ecosystems and resources damage categories. The presented indicators show that the dominant environmental impact $(97 \%)$ results from the production process of hot-rolled sheets. The remaining part of the environmental burden $(2.5-3.3 \%)$ is due to transport. These proportions show that, compared to the production processes, the transport distance from the manufacturer to the installation site has an insignificant impact on the final results. If GU $6 \mathrm{~N}$ steel sheet piles were produced at the location of their application, the overall environmental impact would be reduced by only a few percent. Identical conclusions can be drawn for sheet piles type Larssen 43 (normalization indicators are about twice as high, but the proportions between the environmental impact of sheets production and transport are analogous).

Table 2 shows characterization and normalization indicators for PVC sheet piles. The same results in terms of endpoint indicators are illustrated in Fig. 2 in the form of process networks. The presented values indicate that the environmental impact is dominated by the sheet piles manufacturing (98\%). The process with the highest share is PVC granulate production (84-93\% of the total environmental impact), whereas electricity consumption for polymer extrusion is much less significant (the share is below 15\%). As in the case of steel sheet piles, the share of transport does not exceed a few percent of the total environmental impact.

The comparison of the indicators obtained for steel sheet piles GU 6N and PVC sheet piles clearly shows that the environmental impact of vinyl products is significantly lower than that of steel piles. Depending on the endpoint, the indicators determined for PVC sheet piles are from 2.2 to 4.4 times lower than values obtained for GU $6 \mathrm{~N}$ piles and from 5.2 to 10.4 times lower than those for Larssen 43 piles. The largest differences are observed for the category of ecosystems while the smallest differences has been recorded for the category of resources. The individual indicators for the compared types of sheet piles are shown in Fig. 3.

\section{Uncertainty analysis}

The aim of this section is to estimate uncertainties of the analysis outputs resulting from the uncertainties of input 
Table 1 Characterization and normalization indicators for steel sheet piles

\begin{tabular}{|c|c|c|c|c|c|c|}
\hline \multirow[t]{2}{*}{ Impact category } & \multicolumn{2}{|c|}{ Characterization $^{\mathrm{a}}$} & \multicolumn{2}{|c|}{ Normalization $(-)$} & \multicolumn{2}{|l|}{ Share $(\%)$} \\
\hline & GU 6N & Larssen 43 & GU $6 \mathrm{~N}$ & Larssen 43 & Production & Transport \\
\hline Climate change $^{\mathrm{HH}}$ & $1.15 \mathrm{E}-01$ & $2.73 \mathrm{E}-01$ & $5.71 \mathrm{E}+00$ & $1.36 \mathrm{E}+01$ & 97.8 & 2.2 \\
\hline Ozone depletion $^{\mathrm{HH}}$ & $1.37 \mathrm{E}-06$ & $3.24 \mathrm{E}-06$ & $6.77 \mathrm{E}-05$ & $1.61 \mathrm{E}-04$ & 41.4 & 58.6 \\
\hline Human toxicity ${ }^{\mathrm{HH}}$ & $1.21 \mathrm{E}-03$ & $2.87 \mathrm{E}-03$ & $6.00 \mathrm{E}-02$ & $1.43 \mathrm{E}-01$ & 85.8 & 14.2 \\
\hline Photochemical oxidant formation ${ }^{\mathrm{HH}}$ & $7.98 \mathrm{E}-06$ & $1.89 \mathrm{E}-05$ & $3.96 \mathrm{E}-04$ & $9.40 \mathrm{E}-04$ & 94.0 & 6.0 \\
\hline Particulate matter formation ${ }^{\mathrm{HH}}$ & $1.81 \mathrm{E}-02$ & $4.31 \mathrm{E}-02$ & $9.00 \mathrm{E}-01$ & $2.14 \mathrm{E}+00$ & 95.3 & 4.7 \\
\hline Ionising radiation ${ }^{\mathrm{HH}}$ & $2.80 \mathrm{E}-06$ & $6.64 \mathrm{E}-06$ & $1.39 \mathrm{E}-04$ & $3.29 \mathrm{E}-04$ & 0.0 & 100.0 \\
\hline Climate change $\mathrm{E}^{\mathrm{E}}$ & $6.52 \mathrm{E}-04$ & $1.55 \mathrm{E}-03$ & $3.73 \mathrm{E}+00$ & $8.87 \mathrm{E}+00$ & 97.8 & 2.2 \\
\hline Terrestrial acidification $^{\mathrm{E}}$ & $1.59 \mathrm{E}-06$ & $3.78 \mathrm{E}-06$ & $9.11 \mathrm{E}-03$ & $2.16 \mathrm{E}-02$ & 97.3 & 2.7 \\
\hline Freshwater eutrophication ${ }^{\mathrm{E}}$ & $2.62 \mathrm{E}-08$ & $6.22 \mathrm{E}-08$ & $1.50 \mathrm{E}-04$ & $3.56 \mathrm{E}-04$ & 68.8 & 31.2 \\
\hline Terrestrial ecotoxicity ${ }^{\mathrm{E}}$ & $4.57 \mathrm{E}-07$ & $1.08 \mathrm{E}-06$ & $2.62 \mathrm{E}-03$ & $6.21 \mathrm{E}-03$ & 91.9 & 8.1 \\
\hline Freshwater ecotoxicity ${ }^{\mathrm{E}}$ & $4.78 \mathrm{E}-08$ & $1.13 \mathrm{E}-07$ & $2.74 \mathrm{E}-04$ & $6.50 \mathrm{E}-04$ & 97.1 & 2.9 \\
\hline Marine ecotoxicity ${ }^{\mathrm{E}}$ & $9.31 \mathrm{E}-12$ & $2.21 \mathrm{E}-11$ & $5.33 \mathrm{E}-08$ & $1.27 \mathrm{E}-07$ & 47.8 & 52.2 \\
\hline Agricultural land occupation ${ }^{\mathrm{E}}$ & $9.21 \mathrm{E}-08$ & $2.19 \mathrm{E}-07$ & $5.27 \mathrm{E}-04$ & $1.25 \mathrm{E}-03$ & 0.0 & 100.0 \\
\hline Urban land occupation $^{\mathrm{E}}$ & $3.72 \mathrm{E}-07$ & $8.84 \mathrm{E}-07$ & $2.13 \mathrm{E}-03$ & $5.06 \mathrm{E}-03$ & 0.0 & 100.0 \\
\hline Natural land transformation ${ }^{\mathrm{E}}$ & $1.03 \mathrm{E}-06$ & $2.45 \mathrm{E}-06$ & $5.91 \mathrm{E}-03$ & $1.40 \mathrm{E}-02$ & 0.0 & 100.0 \\
\hline Metal depletion ${ }^{\mathrm{R}}$ & $7.53 \mathrm{E}+00$ & $1.79 \mathrm{E}+01$ & $2.81 \mathrm{E}-04$ & $6.67 \mathrm{E}-04$ & 0.0 & 100.0 \\
\hline Fossil depletion $^{\mathrm{R}}$ & $3.45 \mathrm{E}+05$ & $8.20 \mathrm{E}+05$ & $1.29 \mathrm{E}+01$ & $3.06 \mathrm{E}+01$ & 96.7 & 3.3 \\
\hline
\end{tabular}

${ }^{\mathrm{a}}$ Characterization unit depends on the damage category as follows: HH (human health) [DALY]; E (Ecosystems) [species yr]; R (resources) [\$]
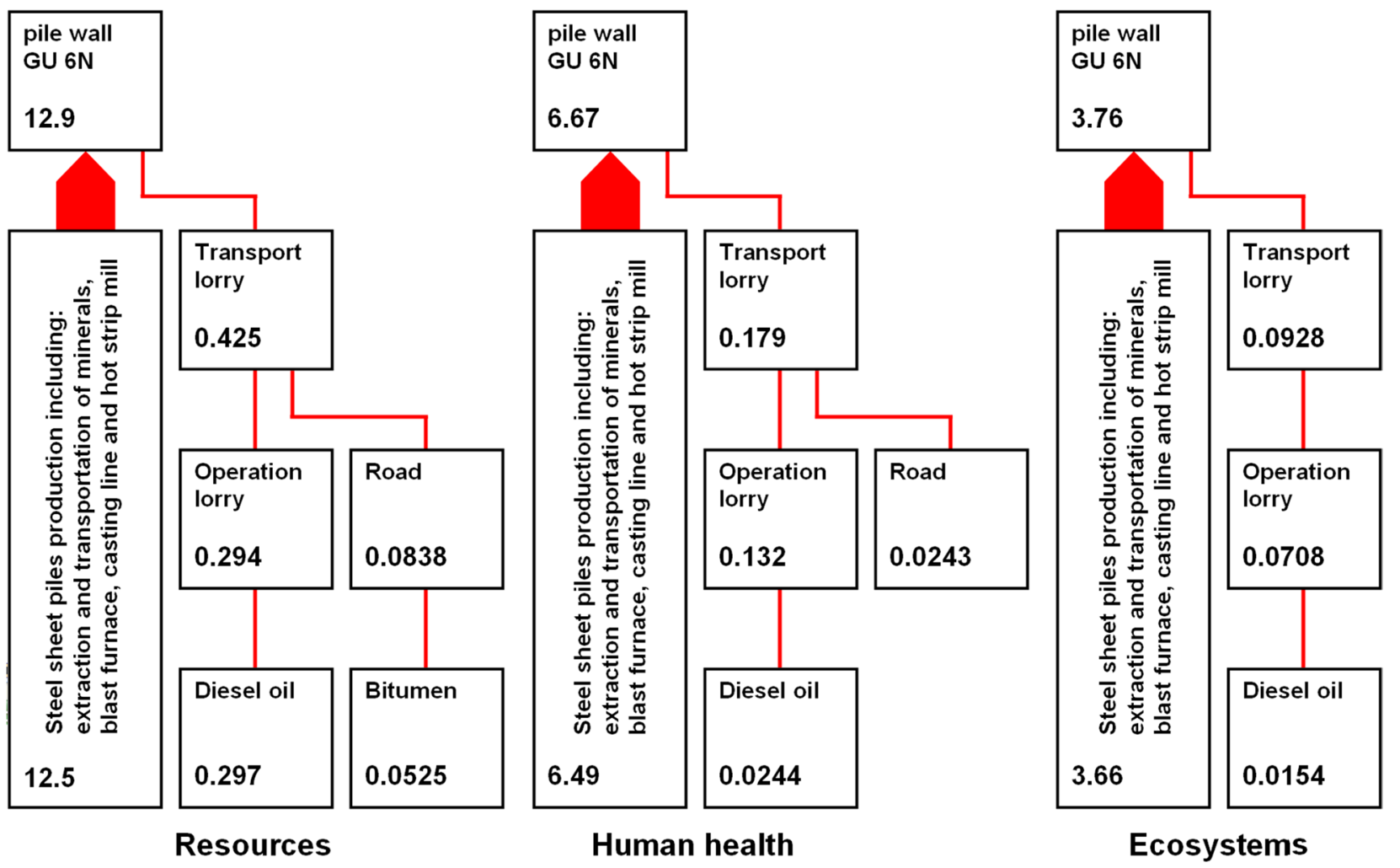

Fig. 1 The process network diagrams obtained for steel sheet piles GU 6N 
Table 2 Characterization and normalization indicators for steel sheet piles

\begin{tabular}{llllr}
\hline Impact category & Characterization & & \\
& & & Normalization & \multicolumn{2}{l}{ Share (\%) } \\
\cline { 3 - 4 } & & & Production & Transport \\
\hline Climate change $^{\mathrm{HH}}$ & $2.62 \mathrm{E}-02$ & $1.30 \mathrm{E}+00$ & 97.8 & 2.2 \\
Ozone depletion $^{\mathrm{HH}}$ & $1.24 \mathrm{E}-06$ & $6.17 \mathrm{E}-05$ & 85.3 & 14.7 \\
Human toxicity $^{\mathrm{HH}}$ & $1.14 \mathrm{E}-03$ & $5.66 \mathrm{E}-02$ & 96.6 & 3.4 \\
Photochemical oxidant formation $^{\mathrm{HH}}$ & $3.33 \mathrm{E}-06$ & $1.65 \mathrm{E}-04$ & 96.7 & 3.3 \\
Particulate matter formation $^{\mathrm{HH}}$ & $5.01 \mathrm{E}-03$ & $2.48 \mathrm{E}-01$ & 96.2 & 3.8 \\
Ionising radiation $^{\mathrm{HH}}$ & $1.24 \mathrm{E}-05$ & $6.18 \mathrm{E}-04$ & 94.9 & 5.1 \\
Climate change $^{\mathrm{E}}$ & $1.48 \mathrm{E}-04$ & $8.49 \mathrm{E}-01$ & 97.8 & 2.2 \\
Terrestrial acidification $^{\mathrm{E}}$ & $3.33 \mathrm{E}-07$ & $1.91 \mathrm{E}-03$ & 97.0 & 3.0 \\
Freshwater eutrophication $^{\mathrm{E}}$ & $2.49 \mathrm{E}-08$ & $1.43 \mathrm{E}-04$ & 92.5 & 7.5 \\
Terrestrial ecotoxicity $^{\mathrm{E}}$ & $8.39 \mathrm{E}-08$ & $4.81 \mathrm{E}-04$ & 89.9 & 10.1 \\
Freshwater ecotoxicity $^{\mathrm{E}}$ & $6.46 \mathrm{E}-09$ & $3.70 \mathrm{E}-05$ & 95.2 & 4.8 \\
Marine ecotoxicity $^{\mathrm{E}}$ & $1.45 \mathrm{E}-11$ & $8.30 \mathrm{E}-08$ & 92.4 & 7.6 \\
Agricultural land occupation $^{\mathrm{E}}$ & $4.61 \mathrm{E}-08$ & $2.64 \mathrm{E}-04$ & 54.5 & 45.5 \\
Urban land occupation $^{\mathrm{E}}$ & $1.82 \mathrm{E}-07$ & $1.04 \mathrm{E}-03$ & 53.3 & 46.7 \\
Natural land transformation $^{\mathrm{E}}$ & $2.95 \mathrm{E}-07$ & $1.69 \mathrm{E}-03$ & 20.3 & 79.7 \\
Metal depletion $^{\mathrm{R}}$ & $4.43 \mathrm{E}+00$ & $1.65 \mathrm{E}-04$ & 61.3 & 38.7 \\
Fossil depletion $^{\mathrm{R}}$ & $1.58 \mathrm{E}+05$ & $5.89 \mathrm{E}+00$ & 98.4 & 1.6 \\
\hline
\end{tabular}

${ }^{\mathrm{a}}$ Characterization units depend on the impact category as follows: HH (human health) [DALY]; E (Ecosystems) [species yr]; R (resources) [\$]
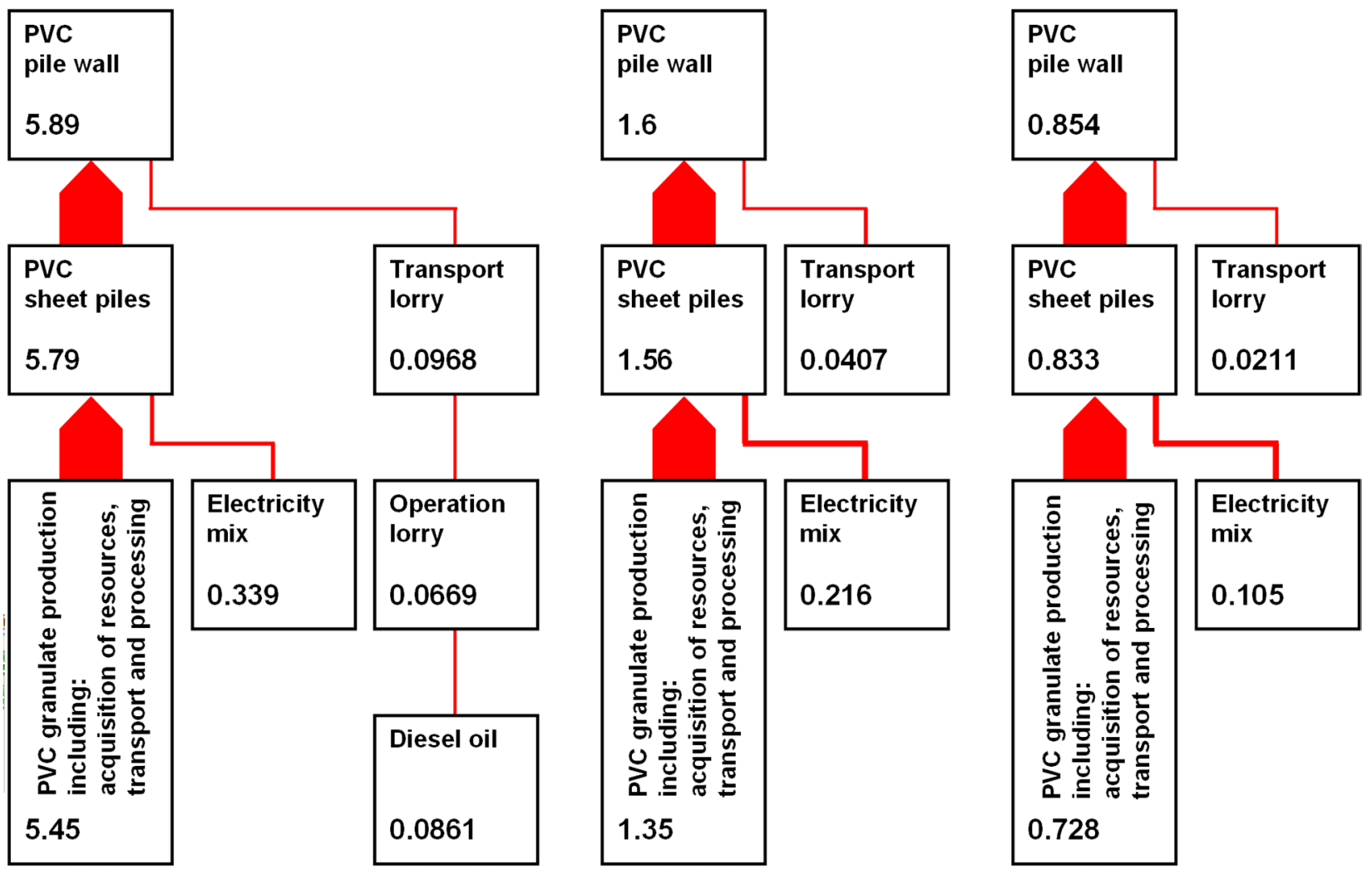

Fig. 2 The process network diagrams obtained for PVC sheet piles 


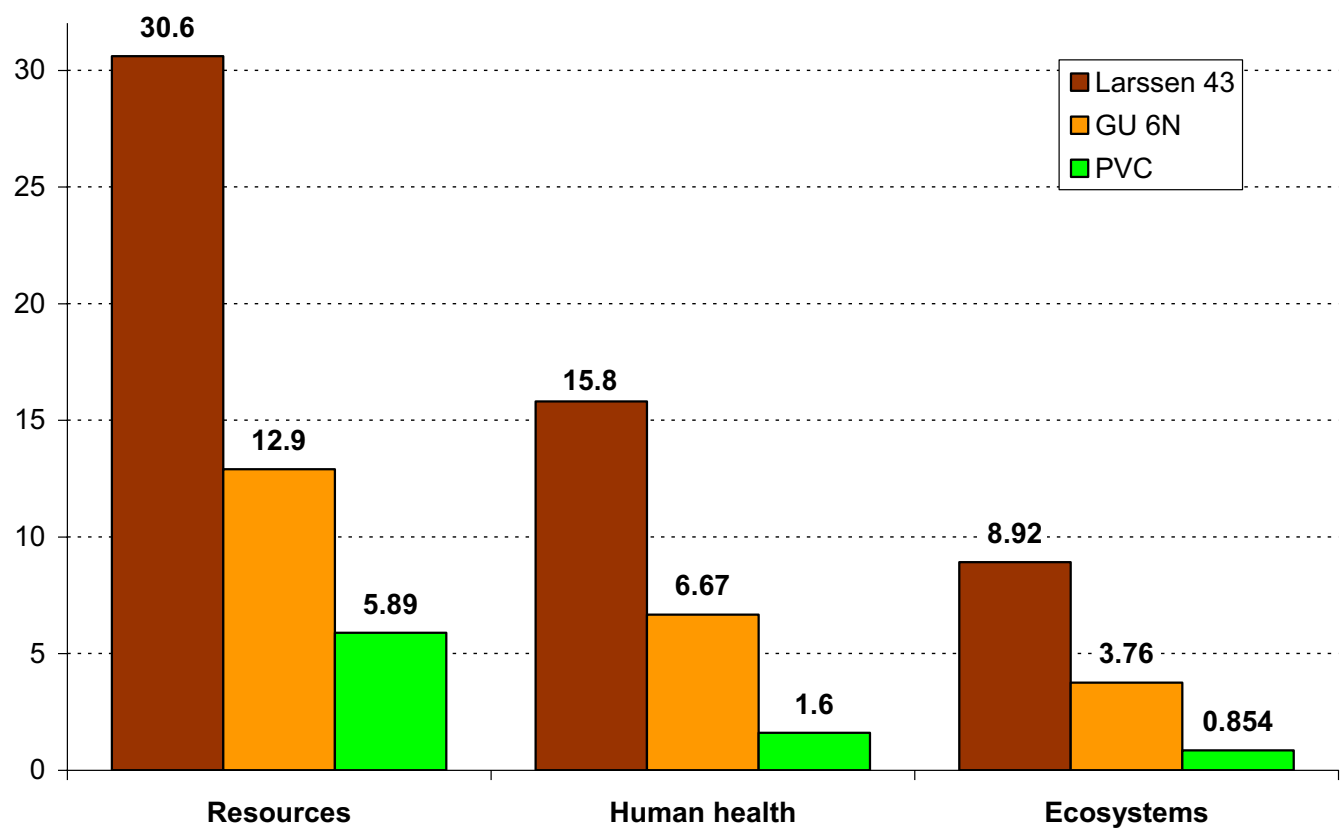

Fig. 3 Normalization indicators for the compared types of sheet piles

parameters of the baseline LCA model. Monte Carlo simulations were applied to generate $95 \%$ confidence intervals for the results. The confidence ranges are depicted in Fig. 4. In case of steel sheet piles absolute relative deviations from the mean values ranged $0.6-2.4 \%$ and were the largest for the damage category of resources. The results of PVC sheet piles indicated significantly greater absolute deviations which varied within a range of $12-19 \%$. As in the case of steel products, the largest deviations were observed for the resources endpoint. However, despite wider confidence intervals, the comparison of the highest indicators for vinyl piles with lowest indicators for GU 6N piles would not change the conclusion drawn: the environmental impact of PVC products is significantly lower than that of steel sheet piles (depending on the damage

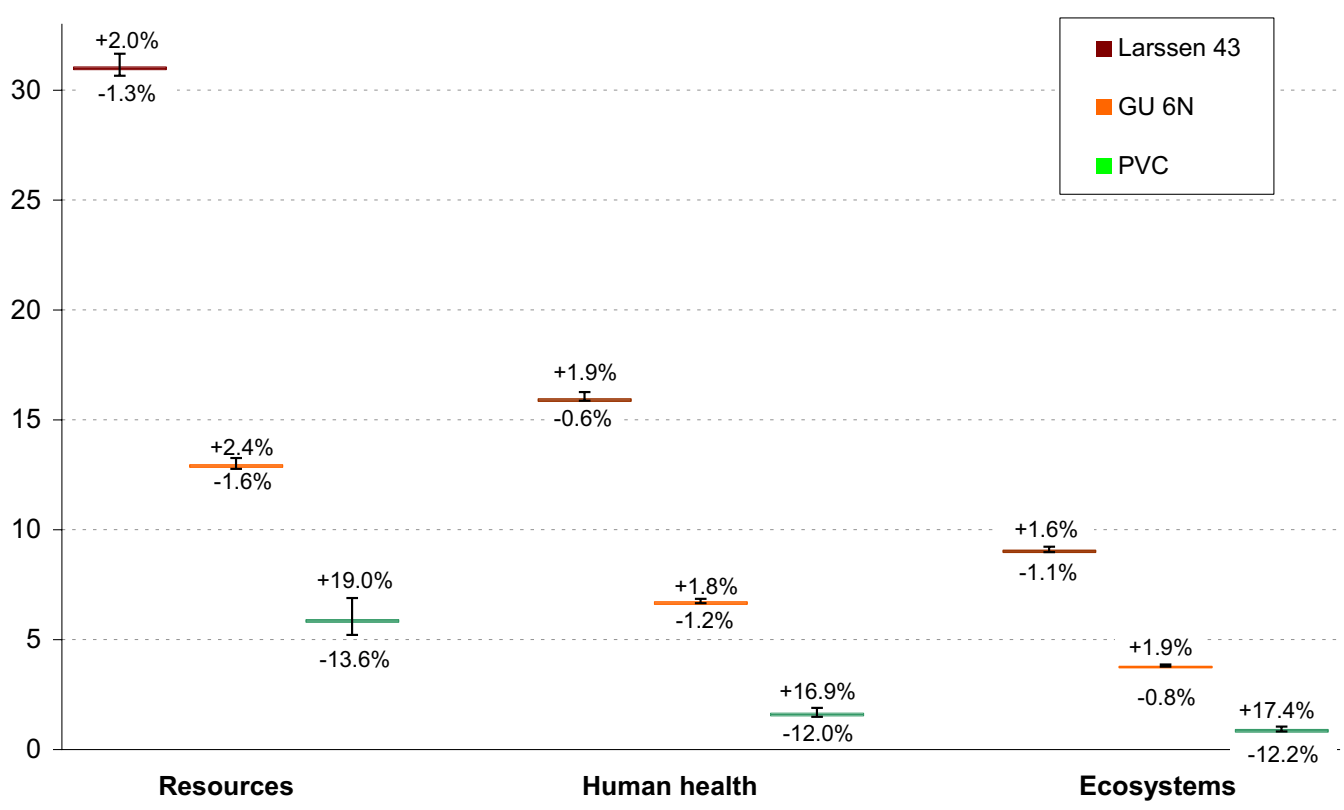

Fig. 4 Confidence intervals for the normalization indicators determined 
category, the indicators obtained for vinyl products are from 1.9 to 3.8 times lower than values for $\mathrm{GU} 6 \mathrm{~N}$ piles).

\section{Sensitivity analysis}

The baseline scenario model involves a few main assumptions that could affect the outcomes and conclusions drawn: the thickness of steel sheet after 50 years of use, corrosion rate, transport distance, emission standard of transportation vehicles.

\section{Thickness of steel sheet after 50 years of use}

According to the assumption 1 (in the "Materials and methods" section), the minimum thickness of steel sheet piles after 50 years of operation is $4.5 \mathrm{~mm}$. As the baseline scenario indicated a substantial advantage of vinyl products over steel products, increasing this value would result in an upscaling of the environmental impact of steel sheet piles and consequently even greater discrepancies in outcomes for both solutions. To test the effect of this assumption on the comparison results, a smaller thickness $t_{50}$ of steel sheets was assumed: $3 \mathrm{~mm}$ (the minimum thickness of cold rolled steel profiles available on the market (InfraRentals 2019; ArcelorMittal 2019a). Including the corrosion loss allowances according to Eq. 1, the initial thicknesses of steel sheet piles, $t_{\text {init }}$, were:

- for the least aggressive environment $t_{\text {init }}=4.2 \mathrm{~mm}$,

- for the most aggressive environment $t_{\text {init }}=10.5 \mathrm{~mm}$.
The products with corresponding parameters, taken for further analyses, were steel sheet piles of the following types:

- ArcelorMittal PAU $22406 \mathrm{~mm}\left(42.3 \mathrm{~kg} / \mathrm{m}^{2}\right)$,

- Larssen $2311.5 / 10 \mathrm{~mm}\left(155.0 \mathrm{~kg} / \mathrm{m}^{2}\right)$ (InfraRentals 2019). Thus, the mass per functional unit is:

- $21.15 \mathrm{t}$-for the least aggressive environment,

- $77.5 \mathrm{t}$ - for the most aggressive environment.

The obtained normalization indicators for the compared types of sheet piles are depicted in Fig. 5. For comparison, the same graph presents the values obtained for baseline scenario (solid bars). The results show that despite the assumed minimum thickness of steel sheet piles, the environmental impact of PVC products is distinctly lower compared to the impact of steel products. In case of steel piles assumed for the least aggressive environment, the differences are not that great as in baseline scenario. For human health and ecosystems damage categories, the indicators determined for PAU 2240 piles are 2.5-2.7 times higher compared to vinyl alternative, but in case of resources endpoint the relative difference equals only $32 \%$. Despite lower differences, the general conclusion remains the same as in the "Baseline scenario" section-steel sheet piles indicate significantly higher environmental impact than PVC sheet piles.

\section{The rate of corrosive processes}

According to the discussed outcomes, the rate of corrosion has a significant impact on the environmental impact

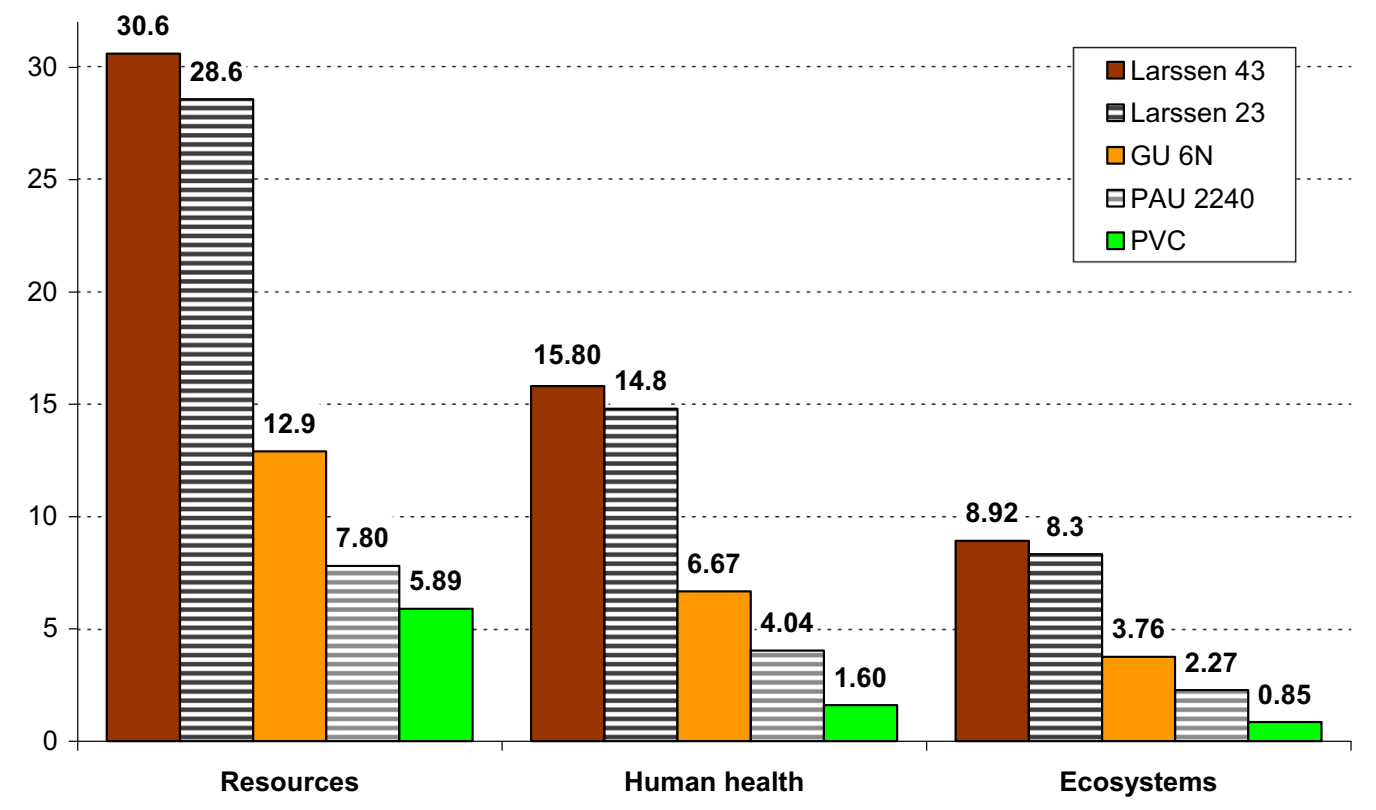

Fig. 5 Normalization indicators assuming $3 \mathrm{~mm}$ thickness of steel sheet piles after 50 years of use 
indicators. The results determined for the most aggressive environment, for which the corrosion rate is the highest, substantially exceed the values obtained for the less aggressive conditions. The indicators concerning sheet piles Larssen 43 and Larssen 23 are 2.4-3.7 higher than those for sheet piles GU 6N and PAU 2240. The assumption of a higher corrosion rate would increase the environmental impact of steel products leading to greater discrepancies between the environmental performance of steel and PVC products. Given this conclusion, the opposite change of the assumption, namely, lower corrosion rate was analyzed in this section. In an extreme case, it could even be assumed that there is no corrosion, but provided the use of the secondary protection technique. In case of not very aggressive environment, like submerged zones, for instance, a corrosion prevention measure such as protective coatings could be sufficiently effective and allow to avoid the application of thickness loss allowances (Ferguson and Trewern 2015). In this regard, the use of 3-mm-thick steel sheet pile (PAL 3030) with coatings was assumed as a material for waterfront construction. As the unit mass of the product is $29.4 \mathrm{~kg} / \mathrm{m}^{2}$ (InfraRentals 2019), the total mass related to the functional unit equals 14.7 t. Figure 6 depicts the comparison of normalization indicators for steel sheet piles coated with zinc or powder and PVC sheet piles. The results show that the vinyl product remains the best choice from the environmental perspective; however, the differences between the values obtained for different sheet piles are markedly lower compared to the data presented above. For human health and ecosystems categories, the indicators determined for steel products are 1.9-2.1 times higher compared to vinyl alternative, but in case of resources endpoint the results are almost the same (the relative difference equals only $0.8-2.0 \%$ ). Excluding the impact of coating processes, the indicator determined for steel piles would be even lower than the value for PVC piles, which is due to a difference within a fossil depletion impact.

\section{Assumptions concerning transport}

The baseline scenario comprised a few assumptions concerning transport processes: transportation distance from sheet piles manufacturer to the place of waterfront construction $(500 \mathrm{~km})$ and means of transport (lorries complying with the emission standard of EURO 4 with a total permissible mass exceeding 32 tons).

In the comment to Fig. 1, it was noticed that the assumed transport distance had an insignificant impact on the final results. If steel sheet piles were produced at the place of their application, the overall environmental impact would be reduced by only a few percent. The same conclusion could also be drawn for vinyl sheet piles. The opposite scenario considering longer transportation distance was also analyzed. Figure 7 depicts normalization indicators for the compared types of sheet piles assuming four times greater transport distance than in the baseline scenario $(2000 \mathrm{~km})$. The bars indicating steel piles are noticeably higher than the bars denoting PVC products. The relative differences are very similar compared to baseline scenario (compare Fig. 3). Depending on the endpoint, the indicators determined for vinyl sheet piles are from 2.3 to 4.4 times lower

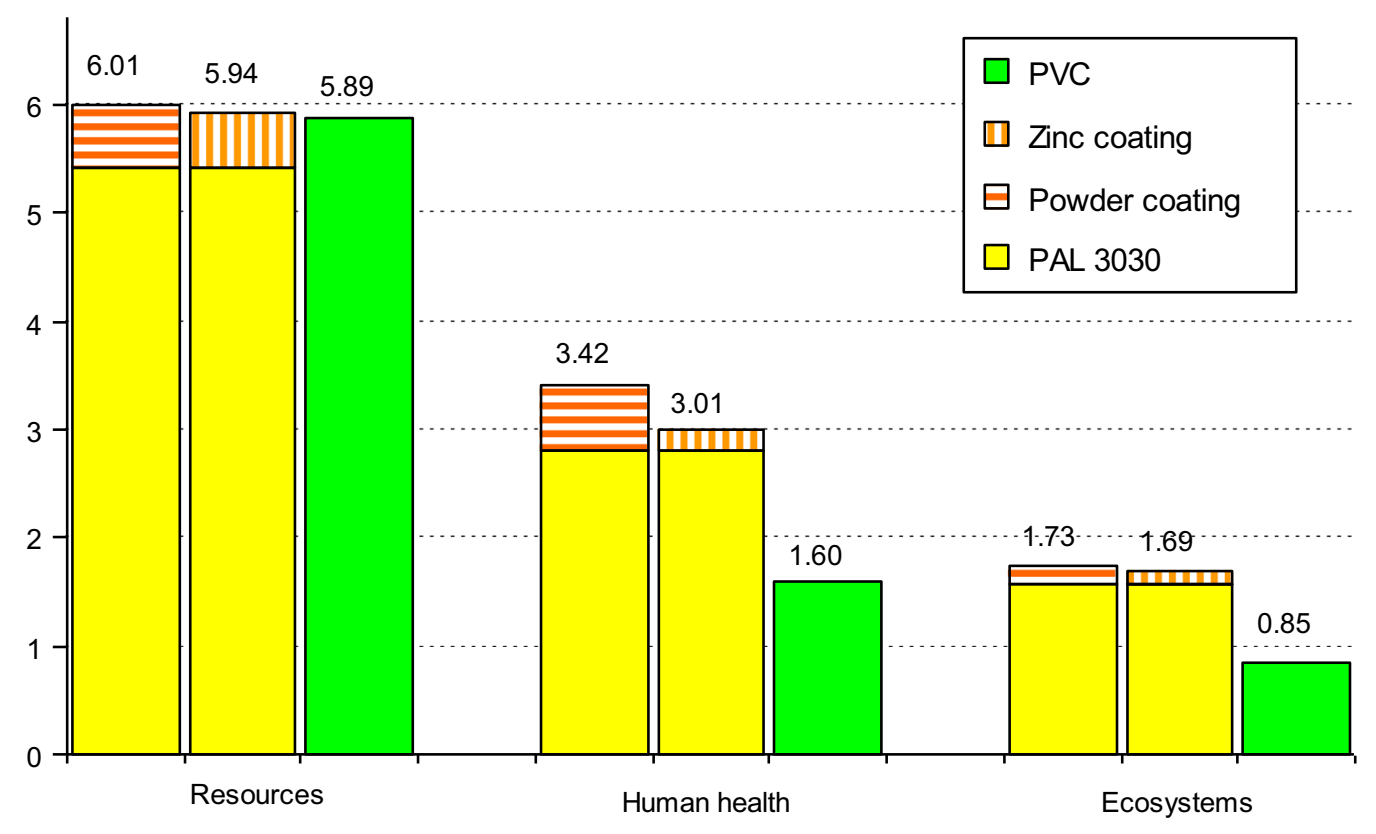

Fig. 6 Normalization indicators for steel sheet piles with coatings and PVC sheet piles 


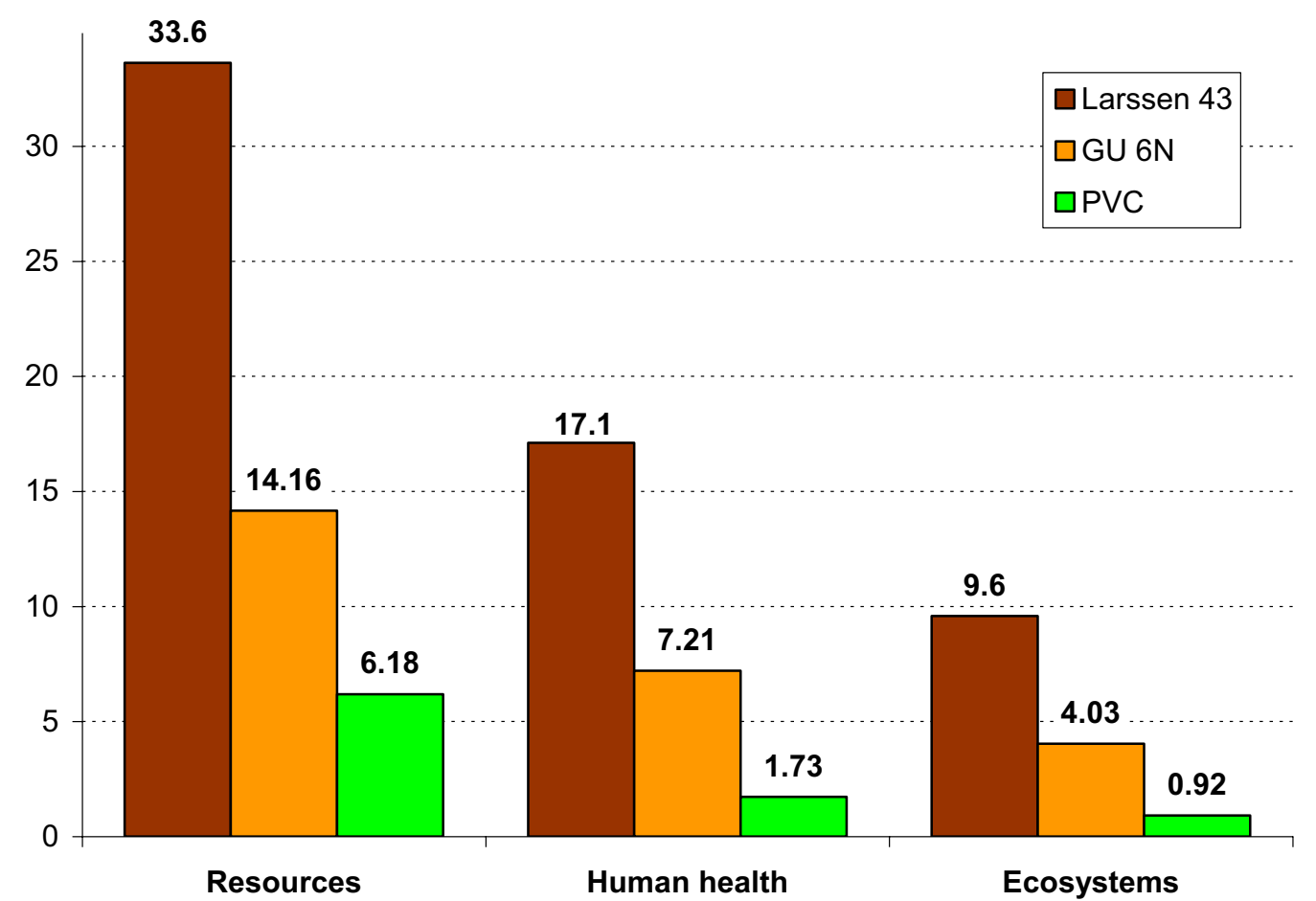

Fig. 7 Normalization indicators assuming transportation distance of $2000 \mathrm{~km}$

than those of GU $6 \mathrm{~N}$ and from 5.4 to 10.4 times lower than values obtained for Larssen 43 . The share of environmental impact resulting from transport does not exceed $10 \%$. The analysis results allow further generalization of conclusions: in the scale of distance corresponding to European region, the environmental impact of transport is insignificant in comparison with the impact of sheet piles production processes. Thus, the assumed transport distances for raw materials, products and waste do not have a crucial impact on the scale of the environmental impact of the entire life cycle.

In order to test the assumption concerning emission standard of transportation vehicles, additional analyses were carried out assuming better and worse standards: EURO 5 and EURO 3. The determined endpoint indicators are presented in Table 3.

The obtained results indicate that the total environmental impact of the life cycle of the sheet piles is almost independent of the assumed emission standard. Relative differences of results range between 0.2 and $0.7 \%$ depending on the damage category. The greatest differences (obtained for human health endpoint) are illustrated in Fig. 8.

\section{Conclusion}

The main objective of this study was to determine and compare the environmental impact of steel and PVC sheet piles using life cycle assessment method. The functional unit was a pile wall with a length of $100 \mathrm{~m}$ made of sheet piles with a vertical dimension of $5 \mathrm{~m}$ used for 50 years in waterfront conditions. A number of assumptions were made to determine the scope of the analysis within the baseline scenario. The environmental impact assessment was determined according to a cradle-to-site approach. Monte Carlo simulations method was used to generate $95 \%$ confidence intervals for the results. Sensitivity analyses were also conducted to assess the resistance of the obtained results to the assumed parameters of the baseline scenario.

Table 3 Normalization indicators obtained for various emission standards

\begin{tabular}{|c|c|c|c|c|c|c|c|c|c|}
\hline \multirow[t]{2}{*}{ Damage category } & \multicolumn{3}{|c|}{ Larssen 43} & \multicolumn{3}{|l|}{ GU 6N } & \multicolumn{3}{|l|}{ PVC } \\
\hline & EURO 3 & EURO 4 & EURO 5 & EURO 3 & EURO 4 & EURO 5 & EURO 3 & EURO 4 & EURO 5 \\
\hline Resources & 30.72 & 30.60 & 30.61 & 12.94 & 12.88 & 12.89 & 5.90 & 5.89 & 5.89 \\
\hline Human Health & 15.93 & 15.84 & 15.83 & 6.71 & 6.67 & 6.66 & 1.61 & 1.60 & 1.60 \\
\hline Ecosystems & 8.95 & 8.92 & 8.92 & 3.77 & 3.76 & 3.76 & 0.86 & 0.85 & 0.85 \\
\hline
\end{tabular}




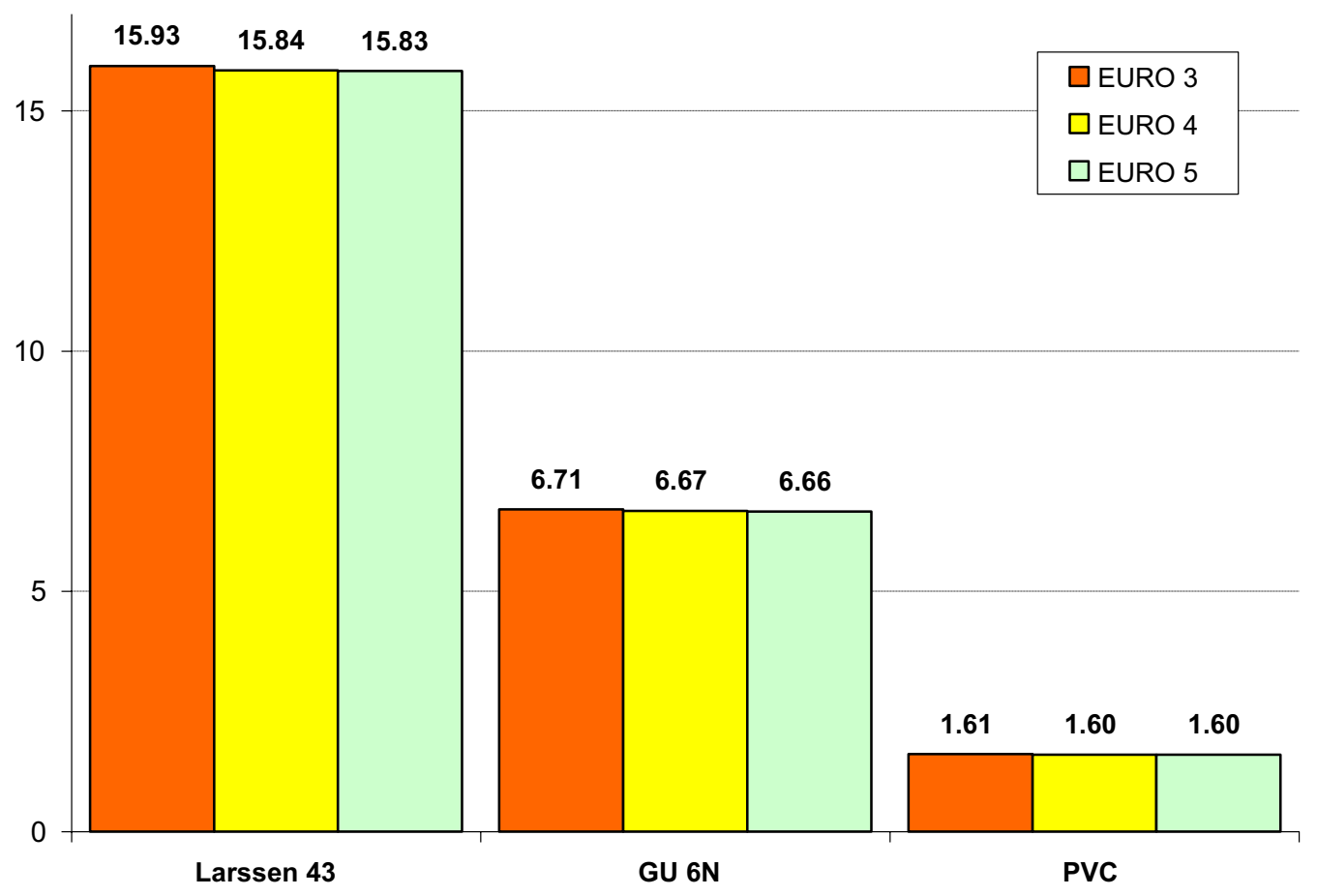

Fig. 8 Human health indicators obtained for different emission standards of transport vehicles

The comparison of the indicators obtained for steel sheet piles and vinyl sheet piles clearly shows that the environmental impact of PVC sheet piles is significantly lower than that of steel sheet piles. In case of damage categories of human health and ecosystems for the most aggressive environment, the differences between the indicators determined for steel and vinyl products reached an order of magnitude. The dominant environmental impact resulted from the production process of sheet piles. The share of environmental burden is due to transport ranged only between 1.6 and 3.3\%. Basing on these proportions a conclusion was drawn that the transport distance from the sheet piles manufacturer to the waterfront construction site had an insignificant impact on the final results. This conclusion was confirmed by sensitivity analysis assuming four times longer transportation distance $(2000 \mathrm{~km})$. The share of transport processes in the entire environmental impact did not exceed $10 \%$. The assumption concerning emission standards of transportation vehicles had an even smaller impact on the results obtained. The relative differences between the normalization indicators determined for lorries complying with EURO 3, EURO 4 and EURO 5 standards amounted to less than $0.7 \%$.

The analyses conducted also included the assessment of sensitivity of the results to the minimum thickness of steel sheet piles after 50 years of use. According to the baseline scenario, the thickness was assumed to be $5 \mathrm{~mm}$. Increasing this value would result in an extended environmental impact of steel sheet piles and consequently greater discrepancies in outcomes for analyzed materials. However, the results obtained assuming the $3 \mathrm{~mm}$ thickness of steel piles after 50 years of operation demonstrated reduced differences between indicators determined for steel and PVC products. Depending on the damage category, the ratio varied in the range 1.3-2.7 (compared to 2.2-4.4 obtained in baseline scenario). Even smaller differences between the results determined for steel and PVC products were observed when assuming the use of 3-mm-thick steel piles coated with zinc or powder protective layers. The ratio of normalization indicators ranged 1.01-1.98 and 1.02-2.13 for powder and zinc coating, respectively, demonstrating almost equal environmental impact in terms of resources depletion.

Despite lower differences, the general conclusion remained unchanged: steel sheet piles indicated markedly higher environmental impact than vinyl sheet piles. The assumptions made for the baseline scenario did not affect the final results significantly.

Acknowledgements The study was carried out within the statutory activity of the Faculty of Management and Production Engineering, Project Number 501-19-910-1-59-58: 'Ocena cyklu życia wybranych obiektów'.

Open Access This article is licensed under a Creative Commons Attribution 4.0 International License, which permits use, sharing, adaptation, distribution and reproduction in any medium or format, as long as you give appropriate credit to the original author(s) and the source, provide a link to the Creative Commons licence, and indicate if changes were made. The images or other third party material in this article are 
included in the article's Creative Commons licence, unless indicated otherwise in a credit line to the material. If material is not included in the article's Creative Commons licence and your intended use is not permitted by statutory regulation or exceeds the permitted use, you will need to obtain permission directly from the copyright holder. To view a copy of this licence, visit http://creativecommons.org/licenses/by/4.0/.

\section{References}

Alamilla JL, Espinosa-Medina MA, Sosa E (2009) Modelling steel corrosion damage in soil environment. Corros Sci 51:2628-2638

ArcelorMittal (2019a) Cold formed steel sheet piles. https://sheet piling.arcelormittal.com/wp-content/uploads/2018/10/AMCRP S_Cold_Formed_SSP_GB_2019_HD-web.pdf. Accessed 16 March 2020

ArcelorMittal (2019b) Steel foundation solutions. https://sheetpilin g.arcelormittal.com/wp-content/uploads/2017/10/AMCRPS General_Catalogue_GB_2019_web.pdf. Accessed 16 March 2020

Bardakjian HH, Olmos J (2018) A case study on design, testing, and installation of two large diameter tunnel liner projects for the City of Los Angeles. In: Pipelines 2018: condition assessment, construction, and rehabilitation-Proceedings of sessions of the pipelines, vol 2018, pp 472-480

Beamer RE, Kendall DR (2009) One agency's perspective on a change from steel to plastic pipe. In: Pipelines 2009: infrastructure's hidden assets-Proceedings of the pipelines 2009 conference, vol 360, pp 1162-1172

Dunalska JA, Grochowska J, Wiśniewski G, Napiórkowska-Krzebietke A (2015) Can we restore badly degraded urban lakes? Ecol Eng $82: 432-441$

Dutta PK, Vaidya UK (2003) An assessment of vinyl sheet piles for long term applications. Proc Int Offshore Polar Eng Conf 2003:2553-2556

European Committee for Standardization (2007) European Standard EN 1993-5 Eurocode 3: Design of steel structures-part 5: piling. CEN National Members, Brussels

Ferguson DP, Trewern CJ (2015) Design challenges associated with the use of non-metallic materials in marine sheet pile walls

Frischknecht R, Jungbluth N, Althaus H-J, Doka G, Dones R, Heck T, Hellweg S, Hischier R, Nemecek T, Rebitzer G, Spielmann M (2005) The ecoinvent database: overview and methodological framework. Int J Life Cycle Assess 10:3-9

Gerritsen RH, Van Regteren DH, Knulst R (2014) Submerged geomembrane systems in Urban Areas: Innovative polder-constructions in limited space. In: 10th International conference on geosynthetics ICG 2014
Houyoux C, Alberts D, Heeling A (2007) Design method for steel structures in marine environment including the corrosion behaviour. European Commission, Directorate-General for Research and Innovation, Luxembourg

InfraRentals (2019) Sharing flexibility. InfraRentals BV. http://www. infrarentals.com/files/infrarentals-brochure-en.pdf. Accessed 30 Dec 2019

International Organization for Standardization (2006a) ISO 14040Environmental management_-Life cycle assessment—Principles and framework

International Organization for Standardization (2006b) ISO 14044Environmental management—Life cycle assessment-Requirements and guidance

Marcinkowski A, Zych K (2017) Environmental performance of kettle production: product life cycle assessment. Manag Syst Prod Eng 25:255-261

Parker V (1992) Suggested guidelines for the use of PTFE, PVC and stainless steel in samplers and well casings. ASTM Spec Tech Publ Issue 1118:217-229

Pietrucha (2018) The EcoLock System. A durable maintenance-free and costs efficient alternative to the traditional solutions. https ://irp-cdn.multiscreensite.com/e446b8c5/files/uploaded/027-16_ Pietrucha_grodzice_EcoLock_eng_hsXpY95NSViD9B4FJ5k5 .pdf. Accessed 30 Dec 2019

Pietrucha Group (2014) Eco-Lock vinyl sheet piles. Pietrucha International. http://shpunt.com.ua/wp-content/uploads/2017/03/ecolo ck_folder_2014_en.pdf. Accessed 30 Dec 2019

Scuero AM, Vaschetti GL (1997) Polyvinylchloride geocomposites as a barrier to seepage and deterioration on old and new dams. In: Varma CVJ, Venkatappa Rao G, Rao ARG (eds) Geosynthetics Asia'97. Balkema, Brookfield, Rotterdam, pp 163-170

Tang Z, Hong S, Xiao W, Taylor J (2006) Characteristics of iron corrosion scales established under blending of ground, surface, and saline waters and their impacts on iron release in the pipe distribution system. Corros Sci 48:322-342

Vaidya UK, Villalobos AA, Serrano-Perez JC, Dutta PK (2005a) Design and analysis of polyvinyl chloride sheetpiles for waterfront protection. In: International SAMPE symposium and exhibition (proceedings) SAMPE 05: new horizons for materials and processing technologies-conference proceedings vol 50, pp $2215-2225$

Vaidya UK, Villalobos AA, Serrano-Perez JC, Dutta PK (2005b) Design and analysis of a PVC seawall system for waterfront protection. Proc Int Offshore Polar Eng Conf 2005:454-462

Wall H, Wadso L (2013) Corrosion rate measurements in steel sheet pile walls in a marine environment. Mar Struct 33:21-32 